\title{
Predicting Winter Wheat Heading Date: A Simple Model and Its Validation in Kansas
}

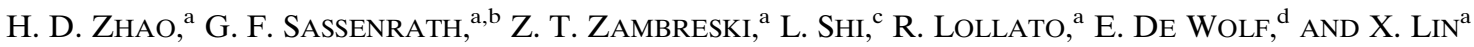 \\ ${ }^{a}$ Department of Agronomy, Kansas Climate Center, Kansas State University, Manhattan, Kansas \\ ${ }^{\mathrm{b}}$ Southeast Research and Extension Center, Parsons, Kansas \\ ${ }^{\mathrm{c}}$ College of Information and Management Science, Henan Agricultural University, Zhengzhou, China \\ ${ }^{\mathrm{d}}$ Department of Plant Pathology, Kansas State University, Manhattan, Kansas
}

(Manuscript received 4 March 2021, in final form 30 August 2021)

\begin{abstract}
Accurate prediction of winter wheat (Triticum aestivum L.) heading date is important for determining the potential incidence of diseases and abiotic stresses such as freeze or heat events. Wheat phenological modeling requires cultivar- and crop-zone-specific vernalization and photoperiod knowledge. Previous models applied in Kansas showed that the uncertainties of predicting heading date were large and could be improved. In this study, a modification to the Scientific Impact Assessment and Modeling Platform for Advanced Crop and Ecosystem Management (SIMPLACE) model was developed and implemented to improve the accuracy of winter wheat heading date estimation. The cultivar- and cropzone-specific model parameters were calculated using a Markov chain Monte Carlo simulation. The modified models were calibrated by using the longest observation site to cover all cultivars planted in each crop zone. Model performance was then evaluated for seven winter wheat cultivars at eight experiment sites distributed across four crop zones in Kansas. Our modified model (MS) had a root-mean-square error (RMSE) between predicted and observed heading date of 4 days, which reflects an improved accuracy by 5-8 days on average compared to the Agricultural Production Systems Simulator (APSIM) or the original SIMPLACE models. There was a clear correlation between the uncertainty of the modeled heading date and the sowing date in previous models. Our modified model demonstrates that integrating nonlinear temperature response functions, temperature stress factors, and sowing date information improved prediction of the heading date in winter wheat across Kansas.
\end{abstract}

KEYWORDS: Atmosphere-land interaction; Climatology; Agriculture; Crop growth

\section{Introduction}

A reliable estimate of winter wheat heading date can be a useful tool in theoretical and practical applications due to the importance of the grain filling period for most commercial crops, in which climate and climate change play critical roles in modulating crop yields and sustaining crop production. Kansas lies in the central portion of the U.S. Great Plains, extending across a $660-\mathrm{km}$ gradient from subhumid climate in the southeast, supporting forests and rain-fed agriculture, to semiarid climate with water-limited agriculture in the west (Lin et al. 2017). For instance, heading date estimates were used to calculate the risks of freeze damage around heading date and heat stress during the grain filling period for winter wheat in the U.S. Great Plains (Lollato et al. 2020). It was also used to explore how wheat cultivars with different maturities and heading dates could avoid freeze damage and heat stress impacts in Australia (Chenu et al. 2013). From a more practical perspective, knowledge of heading date can be used to target fungicide application date, especially for pathogens when fungicide timing is essential. One such pathogen is Fusarium head blight (FHB), which negatively impacts wheat (Triticum aestivum L.) production with up to a $50 \%$ yield reduction, causing significant economic losses for producers especially in high rainfall and/or humid environments (De Wolf et al. 2003; Cowger and Sutton 2005; McMullen et al. 2012; Shah et al. 2013; Jaenisch et al. 2019; Sassenrath et al.

Corresponding author: X. Lin, xlin@ksu.edu
2019). Changes of such critical weather conditions around the winter wheat heading date are extremely sensitive for FHB occurrence (De Wolf et al. 2003). In recent decades, the FHB has reemerged as a disease of global significance, causing yield loss and price discounts as a result of reduced grain quality due to climate change (Chakraborty and Newton 2011; Prank et al. 2019). Therefore, an accurate modeling of winter wheat heading date is a prerequisite in the estimation of FHB incidence, thereby allowing producers to better prepare for proactive and reactive field management.

The literature reports a range of methods to predict wheat heading date, from simple temperature-based models (Chauhan et al. 2019; Lollato et al. 2020) to more complex mechanistic crop simulation models such as the Agricultural Production Systems Simulator (APSIM) and the Scientific Impact Assessment and Modeling Platform for Advanced Crop and Ecosystem Management (SIMPLACE). These models are process-based crop simulation models that rely on both climatological and genetic data to calculate vernalization process and photoperiod for simulating wheat heading date (Bogard et al. 2014; Zheng et al. 2015) and have been broadly used to predict wheat phenology (Ahmed et al. 2016; Rezaei et al. 2018; Wallach et al. 2021). However, approximately $53 \%$ of the variation of heading date modeling can be explained by photoperiod and vernalization factors (Cane et al. 2013), implying that other factors might also contribute to the variations of heading date (HD), for example, sowing date (SD) and crop stress factors. 
Sowing date determines the yield potential of winter wheat as it affects the crop's interaction with biotic and abiotic factors (Munaro et al. 2020) and is one of the agronomic management practices that can improve wheat yields (Nouri et al. 2017). In particular, not only can a later sowing date cause advancement of the heading date in China (He et al. 2015; Liu et al. 2018), Australia (French et al. 1979; Cossani and Sadras 2021), and the Great Plains in the United States (Zambreski 2020), the thermal time accumulated prior to heading date would also be reduced (Paul and Sarker 2000; Yajam and Madani 2013). Such sowing date shifts could introduce additional uncertainties in current phenological modeling. For example, the uncertainties between observed and estimated heading dates in winter wheat by the APSIM model were positively correlated with delayed sowing dates $(\mathrm{Wu}$ et al. 2017; Hussain et al. 2018).

In addition to sowing date, the temperature response function used to calculate daily thermal time can affect heading date modeling in winter wheat. The linear temperature response function can cause additional errors in the phenology model as a biological system response to temperature changes should not be a step or abrupt change but a smooth and continuous development (Ritchie and Nesmith 1991; Shaykewich 1995; Streck et al. 2003). In recent studies, a nonlinear thermal performance curve (TPCs) consisting of both Gaussian rise and parabolic fall on both sides of the optimum temperature was introduced to the population growth model enabling better estimates of crop growth rates under a changing climate (Deutsch et al. 2008; Vasseur et al. 2014; Bernhardt et al. 2018). With increasing likelihood of a warming, shifted precipitation pattern, and more variable climate conditions (Chakraborty and Newton 2011), there is an increasing interest in improving winter wheat phenology modeling to better adapt to the anticipated climate changes in agricultural production system (Prank et al. 2019).

The objective of this study was to modify the SIMPLACE model by implementing a nonlinear thermal performance curve to minimize the abrupt changes at transition points of the response function to temperature and introducing a sowing date shift factor in winter wheat heading date modeling in Kansas. The modified model was calibrated and evaluated using seven specific winter wheat cultivars at 12 experiment sites independently across Kansas over at least 10 -yr growing season windows. The performance of the modified models was then evaluated against the original APSIM and SIMPLACE phenology models.

\section{Materials and methods}

\section{a. Wheat phenological data and weather data}

Seven winter wheat cultivars were selected in this study: Jagger, Karl 92, lke, TAM110, T81, 2174, and 2137, based on the long-term availability of crop testing datasets in Kansas. Crop data were collected from the Kansas Crop Performance Testing Program conducted through the Kansas Agricultural Experiment Station (https://www.ksre.k-state.edu/historicpublications/ report-progress.html) at 12 experiment sites distributed across the four crop zones in Kansas (Fig. 1). These crop zones were selected because they differ considerably in growing season weather, ranging from cool semiarid in the northwest [ 200mm growing-season precipitation and $\sim 800$-mm growing-season reference evapotranspiration (ETo)] to moist subhumid in the southeast ( $\sim 650$-mm seasonal precipitation and $\sim 600-\mathrm{mm}$ seasonal ETo) (Lollato et al. 2017). The crop zones in Kansas have been identified based on the predominant cropping conditions within each region (Shroyer et al. 1996), and range from the cool, dry region in northwest Kansas (zone 1) to the warm, humid region in southeast Kansas (zone 4). The crop data included sowing and heading dates from 1996 to 2012. Available datasets and years of data for each cultivar at each site are shown in Fig. 1. Daily weather data from 1996 to 2012 were taken from the PRISM Climate Group (https://prism. oregonstate.edu/) for the daily maximum temperature $\left({ }^{\circ} \mathrm{C}\right)$, daily minimum temperature $\left({ }^{\circ} \mathrm{C}\right)$, and 24 -h rainfall $(\mathrm{mm})$. The daily snow depth data were taken from the U.S. Historical Climatology Network (Menne et al. 2009; Lin et al. 2017).

The life cycle of wheat (Triticum aestivum L.) progresses through the typical stages of plant production, including vegetative, reproductive, and maturation. Winter wheat seeds are sown in the fall and plants grow and produce vegetative tillers from a portion of the root system referred to as the "crown." Vernalization is a required process in winter wheat that triggers physiological processes in the plant that allow the plant to become reproductive. During vernalization, the wheat is exposed to low temperatures for a period of time. During this stage of development, the plant growth is not as sensitive to low temperatures as in later stages of development. As temperatures increase with spring warming, the wheat goes through a rapid period of vegetative growth called "green up," followed by development of the reproductive structures (the wheat "head"). Following heading, the wheat flowers bloom, pollination occurs, and the wheat heads then mature. Wheat is harvested at maturity when the seeds have dried sufficiently. Heat stress, cold damage, and drought affect winter wheat differently during each stage of growth. This is particularly critical for winter wheat production in Kansas, as the winter and spring temperatures have increased faster than temperatures during the summer season in this region (Lin et al. 2017). The historical state-level phenology data from 1952 to 2020 in Kansas were extracted from the U.S. Department of Agriculture's National Agricultural Statistical Services (USDA-NASS) Crop Progress Report (http://quickstats. nass.usda.gov/) (Fig. 2). The crop progress was reported weekly as growing progress percentages for the entire state, and thus a logistic model was used to estimate a phenological stage when $50 \%$ of the acreage across Kansas was reached (Tollenaar et al. 2017). The historical data shown in Fig. 2 suggest that sowing dates have become later but heading dates have trended toward earlier dates. We note that in historical time scales for the state of Kansas (Fig. 2), the delay in wheat sowing date may be a consequence of a combination of warming air temperature in winter (Sacks et al. 2010) and of a greater adoption of summer crops that are harvested after the optimum sowing date for wheat (Staggenborg et al. 2003). The earlier heading date is attributed to a warmer spring $(\mathrm{Hu}$ 


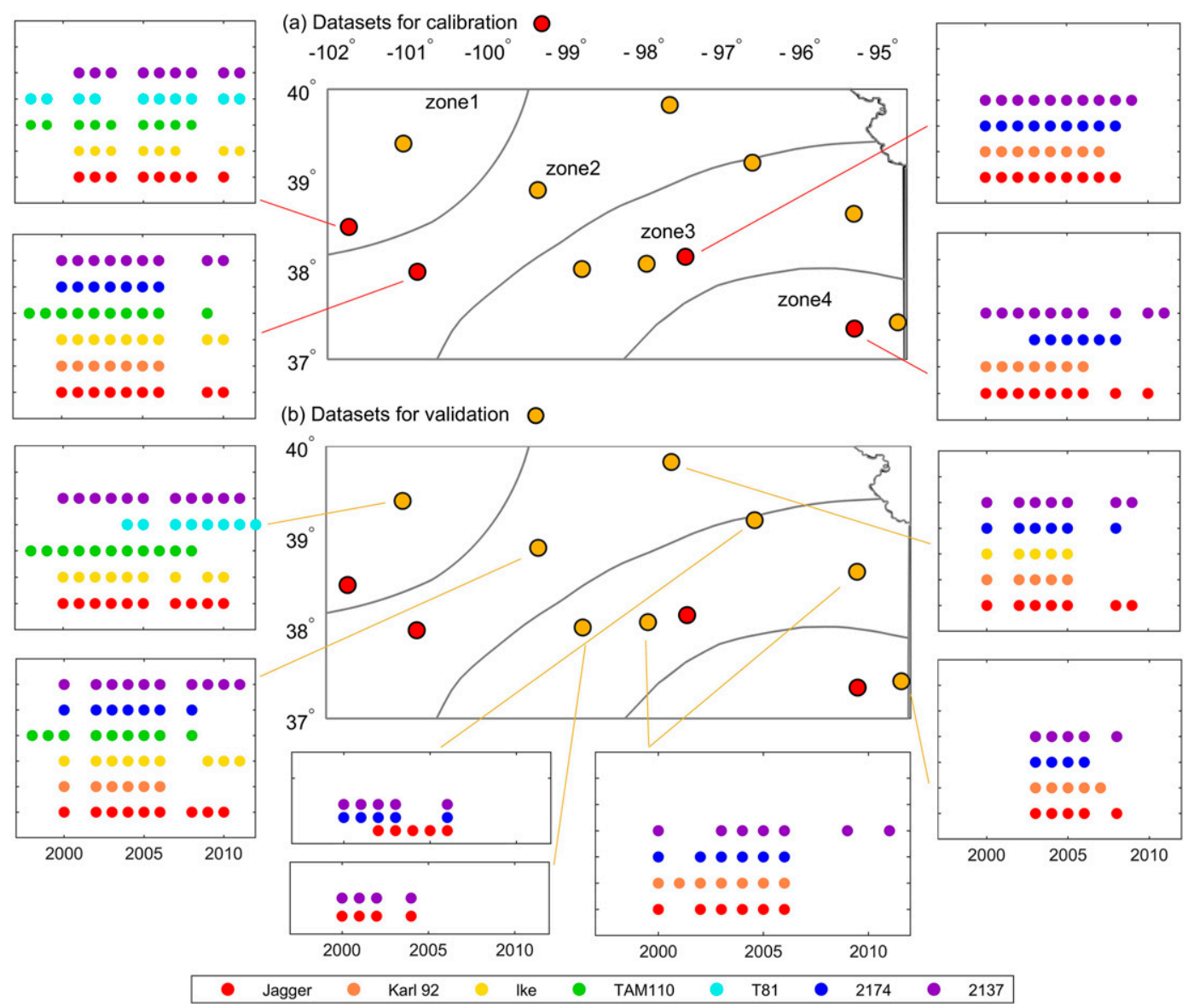

FIG. 1. Datasets analyzed (a) to calibrate model parameters from four experiment sites (red circles) and (b) to validate model performance from eight experimental sites (yellow circles) for seven winter wheat cultivars across the four crop zones (light black lines) in Kansas from 1996 to 2012.

et al. 2005) and to earlier-maturing cultivars, especially during the 1960-90 period (Maeoka et al. 2020).

\section{b. APSIM-wheat and SIMPLACE models}

The APSIM phenology module (Zheng et al. 2015) calculates thermal time $\left(\mathrm{PVT}_{t},{ }^{\circ} \mathrm{C}\right.$ days) using daily thermal time $(\Delta \mathrm{TT}$, ${ }^{\circ} \mathrm{C}$ ) estimated by crown temperature, vernalization and photoperiod to estimate winter wheat heading date by Eqs. (1)-(7). The crown temperature is defined as the soil temperature in the wheat rosette in the topsoil (usually around $5 \mathrm{~cm}$ below the ground surface) and is derived from daily maximum or minimum temperature along with snow cover information.

$$
\begin{aligned}
& T_{\text {cmax }, i}=\left\{\begin{array}{cc}
T_{\max , i} & T_{\text {max }, i} \geq 0^{\circ} \mathrm{C} \\
2+T_{\max , i}\left[0.4+0.0018\left(H_{\text {snow }, i}-15\right)^{2}\right] & T_{\text {max }, i}<0^{\circ} \mathrm{C}
\end{array},\right. \\
& T_{c \min , i}=\left\{\begin{array}{cc}
T_{\min , i} & T_{\min , i} \geq 0^{\circ} \mathrm{C} \\
2+T_{\min , i}\left[0.4+0.0018\left(H_{\mathrm{snow}, i}-15\right)^{2}\right] & T_{\min , i}<0^{\circ} \mathrm{C}
\end{array},\right.
\end{aligned}
$$

$$
\begin{gathered}
T_{c, i}=\frac{T_{c \mathrm{max}, i}+T_{c \mathrm{~min}, i}}{2}, \\
\Delta \mathrm{TT}_{i}=\left\{\begin{array}{cc}
0 & T_{c, i} \leq 0^{\circ} \mathrm{C} \text { or } T_{c, i}>34^{\circ} \mathrm{C} \\
\frac{26}{8}\left(34-T_{c, i}\right) & 26^{\circ}<T_{c, i} \leq 34^{\circ} \mathrm{C} \\
T_{c, i} & 0^{\circ}<T_{c, i} \leq 26^{\circ} \mathrm{C}
\end{array}\right. \\
f_{V, i}=1-\left(0.0054545 V_{\mathrm{sat}}+0.0003\right)\left(50-\mathrm{VDD}_{i}\right), \\
f_{P, i}=1-0.002 P_{\mathrm{base}}\left(P_{\mathrm{opt}}-\mathrm{ph}_{i}\right)^{2}, \text { and }
\end{gathered}
$$

where $i$ refers to Julian day ( $i=1$ is defined as the emergence date), $n$ is observed heading date (days), and $T_{\max }$ and $T_{\min }$ are maximum and minimum air temperature $\left({ }^{\circ} \mathrm{C}\right)$, with $H_{\text {snow }}$ defining snow depth $(\mathrm{cm})$ and $T_{c \max }, T_{c \text { min }}$, and $T_{c}$ being the 

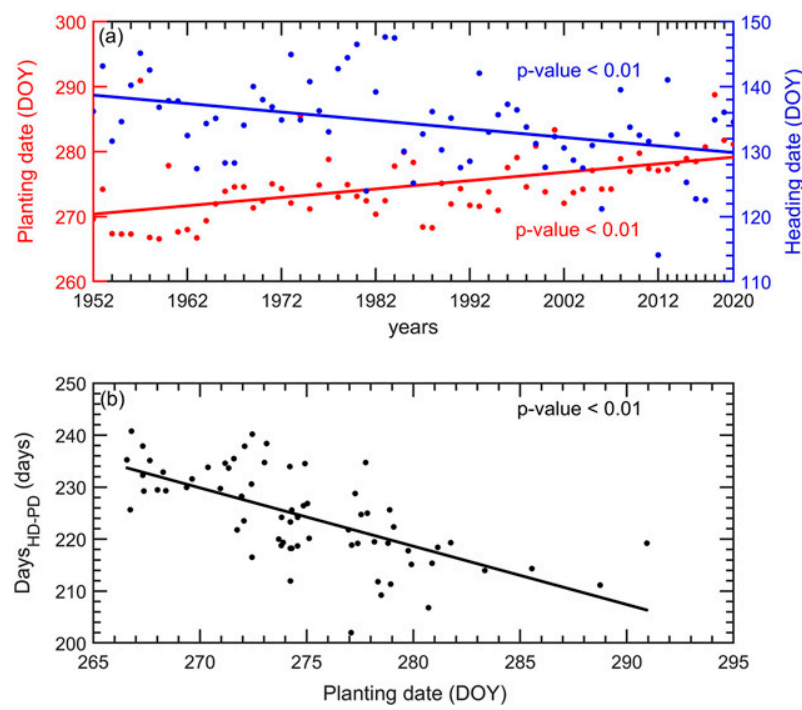

FIG. 2. Annual observed SDs, HDs, and different days between HDs and SDs from 1952 to 2020 in Kansas. (a) SDs (red) and HDs (blue) with least squares trend lines. (b) Days between HD and SD with a linear regression line (black line).

maximum, minimum, and mean crown temperatures $\left({ }^{\circ} \mathrm{C}\right)$. The $0^{\circ}, 26^{\circ}$, and $34^{\circ} \mathrm{C}$ values are cardinal temperatures, respectively (Zheng et al. 2015). Also, $V_{\text {sat }}$ represents cultivarand zone-specific sensitivity of vernalization, VDD refers to accumulated vernalization days in the $i$ th day, $P_{\text {base }}$ and $P_{\text {opt }}$ indicate basal and optimum photoperiods (h), and ph denotes daily actual photoperiod (h).

The SIMPLACE model (Bogard et al. 2014) employs a similar calculation for estimating heading date but uses ambient air temperature instead of crown temperature. The SIMPLACE calculations uses both $f_{V}$ and $f_{P}$ that are cultivar- and cropzone-dependent parameters [Eqs. (8)-(11)]. In APSIM, the $\mathrm{PVT}_{t}$ accounts for the minimum of vernalization and photoperiod factors in the calculation [Eqs. (1)-(7)]. The thermal time $\left(\mathrm{PVT}_{t}\right)$ calculation for the SIMPLACE model is

$$
\begin{gathered}
\Delta T T_{i}=\left\{\begin{array}{cc}
0 & T_{a, i} \leq 1^{\circ} \mathrm{C} \text { or } T_{a, i} \geq 37^{\circ} \mathrm{C} \\
26 \frac{\left(T_{a, i}-1\right)}{(26-1)} & 1^{\circ}<T_{a, i} \leq 26^{\circ} \mathrm{C} \\
26 \frac{\left(37-T_{a, i}\right)}{(37-26)} & 26^{\circ} \mathrm{C}<T_{a, i} \leq 37^{\circ} \mathrm{C}
\end{array}\right. \\
f_{V, i}=\frac{\left(\mathrm{VDD}_{i}-V_{\mathrm{base}}\right)}{\left(V_{\mathrm{sat}}-V_{\mathrm{base}}\right)} \\
f_{P, i}=\frac{\left(p h_{i}-P_{\mathrm{base}}\right)}{\left(P_{\mathrm{opt}}-P_{\mathrm{base}}\right)}, \text { and } \\
\mathrm{PVT}_{t}=\sum_{i=1}^{n}\left(\Delta \mathrm{TT}_{i} \times f_{V, i} \times f_{P, i}\right)
\end{gathered}
$$

where $T_{a}$ is air temperature $\left({ }^{\circ} \mathrm{C}\right), 1^{\circ}, 26^{\circ}$, and $37^{\circ} \mathrm{C}$ represent cardinal temperatures, respectively (Bogard et al. 2014), and $V_{\text {base }}$ and $V_{\text {sat }}$ refer to basal (30 days) and vernalization days (days).

Note that both APSIM and SIMPLACE calculated $\mathrm{PVT}_{t}$ starting from emergence dates (i.e., $i=1$ ) but very limited emergence date data were available. By using available sowing dates and emergence dates (Thiry et al. 2002), an average thermal time to reach emergence dates was estimated as $200^{\circ} \mathrm{C}$ days when using the APSIM-wheat but $130^{\circ} \mathrm{C}$ days when using the SIMPLACE model from the Kansas datasets. Therefore, in this study we used $200^{\circ} \mathrm{C}$ days in APSIM using crown temperature but $130^{\circ} \mathrm{C}$ days in SIMPLACE model using air temperature to calculate the emergence dates at each site. As a result, $i=1$ represented the dates coinciding with the emergence dates in Eqs. (1)-(11). It should be noted that these constant thermal time units between the sowing date and the emergence date across Kansas were defined as $50 \%$ of plant emergence at experiment sites, while thermal time showed a constant value across certain spatial ranges (Jong and Best 1979; McMaster et al. 1992; Kawakita et al. 2020).

\section{c. Modified SIMPLACE model}

The modified model based on the original SIMPLACE was developed in four steps: 1) substituting the linear temperature response function [Eq. (9)] with nonlinear TPCs [Eq. (13)] to calculate daily thermal time (Vasseur et al. 2014) (Fig. 3); 2) adding a temperature stress factor $\left(T_{S}\right)$ to the SIMPLACE model to regulate TPCs (Williams et al. 1989); 3) calibrating basal temperature for each cultivar and each zone so that the modified model will have nonconstant basal temperatures across Kansas (Fig. 3); and 4) incorporating the sowing date into the SIMPLACE model based on the relationship between sowing and heading dates (Figs. 2 and 3). The modified SIMPLACE (MS) can then be described by Eqs. (12)-(15):

$$
\Delta \mathrm{TT}_{i}=\left\{\begin{array}{cc}
0 & T_{a, i} \leq T_{\text {base }} \text { or } T_{a, i} \geq 37^{\circ} \mathrm{C} \\
26\left[\exp \left(-\frac{T_{a, i}-26}{2 \sigma_{p}}\right)^{2}\right] & T_{\text {base }}<T_{a, i} \leq 26^{\circ} \mathrm{C} \\
26\left[1-\left(\frac{T_{a, i}-26}{37-26}\right)^{2}\right] & 26^{\circ}<T_{a, i} \leq 37^{\circ} \mathrm{C}
\end{array}\right.
$$

$$
\begin{gathered}
T_{S, i}=\sin \left(\frac{\pi}{2} \frac{T_{a, i}-T_{\text {base }}}{26-T_{\text {base }}}\right), \\
f_{\mathrm{SD}}=k_{\mathrm{SD}}\left(\mathrm{SD}-\mathrm{SD}_{\text {base }}\right), \text { and } \\
\mathrm{PVT}_{t}=\sum_{i=1}^{n}\left(\Delta \mathrm{TT}_{i} \times f_{V, i} \times f_{P, i} \times T_{S, i}\right)+f_{\mathrm{SD}},
\end{gathered}
$$

where $\sigma_{p}$ is a shape parameter determining the steepness of plant population growth rates. Both $26^{\circ}$ and $37^{\circ} \mathrm{C}$ define the 


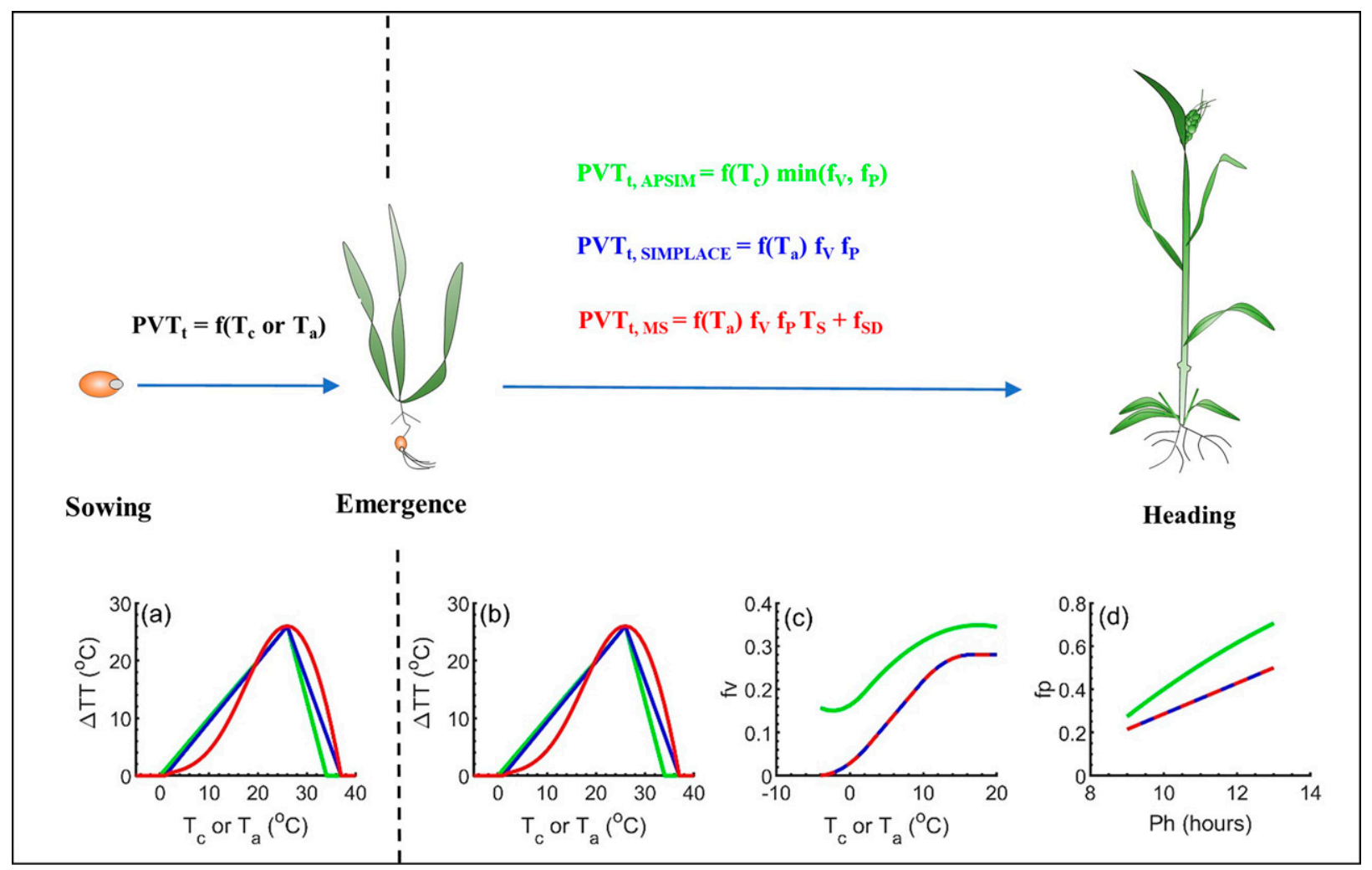

FIG. 3. Schematic diagram of APSIM (green), SIMPLACE (blue), and MS (red) models. The response of winter wheat development to (a),(b) temperature, (c) vernalization, and (d) photoperiod from three models at both seedling and vegetative growth stages.

optimum and maximum temperature and $T_{\text {base }}$ refers to basal temperature $\left({ }^{\circ} \mathrm{C}\right)$ that was determined for each cultivar and crop zone. The nonlinear temperature response functions are illustrated in Fig. 3. The $T_{S}$ denotes the temperature stress factor, which reflected how the actual daily temperature deviated from the optimum temperature (difference). The $f_{\mathrm{SD}}$ is a sowing date factor $\left({ }^{\circ} \mathrm{C}\right.$ days). The $k_{\mathrm{SD}}$ is an adjusting parameter $\left({ }^{\circ} \mathrm{C}\right.$ day $\left.^{-1}\right)$ of $\mathrm{PVT}_{t}$ due to a difference between a specific $\mathrm{SD}$ (days) and the earliest sowing date observed in Kansas $\left[\mathrm{SD}_{\text {base }}\right.$, the day of year $(\mathrm{DOY})=257$ days]. Both vernalization and photoperiod processes and estimation of emergence dates follow the original SIMPLACE model.

\section{d. Model calibration and validation}

The datasets selected in this study were split into calibration data for developing models and validation data for testing models at each specific site for each cultivar. The calibration datasets were obtained from one experiment site selected in each crop zone based on the longest period of available phenology data within each zone (Fig. 1a). Datasets obtained from the remaining experiment sites in each crop zone were used to test model performance (Fig. 1b). The cultivar parameters and their corresponding ranges are shown in Table 1. The Markov chain Monte Carlo (MCMC) method was used to estimate the posterior probability density function of model parameters (Vrugt et al. 2008). The optimal parameter values estimated were based on a minimum rootmean-square error (RMSE) between estimated and observed heading dates that were achieved during the parameter estimation process (Table 2). A total of four sites and at least eight years, including all cultivars, were used for calibration. Eight sites and at least 6 years for all cultivars were used for validation and were independent datasets (Fig. 1). The statistic

TABLE 1. Cultivar parameter ranges in three phenology models for estimating winter wheat heading dates.

\begin{tabular}{cclc}
\hline \hline Parameters & Ranges of parameter & \multicolumn{1}{c}{ Definition } \\
\hline $\mathrm{PVT}_{t}$ & {$[300,1000]$} & Thermal time required from emergence to heading date & Unit \\
$T_{\text {base }}$ & {$[-5,5]$} & Base temperature & ${ }^{\circ} \mathrm{C}$ days \\
$P_{\text {base }}$ & {$[0,10]$} & Base photoperiod & ${ }^{\circ} \mathrm{C}$ \\
$V_{\text {sat }}$ & {$[30,130]$} & Full vernalization days & $\mathrm{h}$ \\
$\sigma_{p}$ & {$[0,10]$} & Shape parameter determining wheat growth rate & ${ }^{\circ} \mathrm{C}$ \\
$k_{\mathrm{PD}}$ & {$[0,10]$} & Coefficient for sowing date changes & ${ }^{\circ} \mathrm{C}$ day ${ }^{-1}$ \\
\hline
\end{tabular}


TABLE 2. List of MS model parameters for seven cultivars across four crop zones in Kansas.

\begin{tabular}{|c|c|c|c|c|c|c|c|}
\hline \multirow[b]{2}{*}{ Zones } & \multirow[b]{2}{*}{ Cultivars } & \multicolumn{6}{|c|}{ Parameters in MS model } \\
\hline & & $T_{\text {base }}\left({ }^{\circ} \mathrm{C}\right)$ & $P_{\text {base }}(\mathrm{h})$ & $\sigma_{p}\left({ }^{\circ} \mathrm{C}\right)$ & $k_{\mathrm{PD}}\left({ }^{\circ} \mathrm{C} \mathrm{day}^{-1}\right)$ & $V_{\text {sat }}$ (days) & $\mathrm{PVT}_{t}\left({ }^{\circ} \mathrm{C}\right.$ days $)$ \\
\hline \multirow[t]{5}{*}{1} & Jagger & -1.1 & 5.9 & 5.9 & 8.1 & 72 & 440 \\
\hline & lke & 1.4 & 6.3 & 6.6 & 7.6 & 89 & 390 \\
\hline & TAM110 & -0.3 & 3.9 & 6.4 & 7.9 & 102 & 380 \\
\hline & T81 & 1.3 & 4.3 & 5.6 & 8.2 & 85 & 370 \\
\hline & 2137 & 0.8 & 6.3 & 5.8 & 7.6 & 77 & 420 \\
\hline \multirow[t]{6}{*}{2} & Jagger & -1.3 & 6.4 & 7.5 & 7.5 & 80 & 460 \\
\hline & Karl 92 & -0.4 & 5.9 & 8.2 & 7.5 & 81 & 500 \\
\hline & lke & 0.4 & 5.5 & 8.1 & 7.6 & 95 & 485 \\
\hline & TAM110 & 0.1 & 6.2 & 7.9 & 7.5 & 86 & 450 \\
\hline & 2174 & 0.6 & 6.5 & 7.6 & 7.6 & 81 & 470 \\
\hline & 2137 & 0.3 & 5.9 & 8 & 8.2 & 87 & 510 \\
\hline \multirow[t]{4}{*}{3} & Jagger & -0.5 & 4.9 & 8.6 & 6.8 & 62 & 540 \\
\hline & Karl 92 & 0.01 & 5.7 & 7.9 & 5.6 & 60 & 455 \\
\hline & 2174 & -0.5 & 7.9 & 8.7 & 6.1 & 46 & 460 \\
\hline & 2137 & -0.3 & 7.1 & 8.7 & 6.1 & 67 & 445 \\
\hline \multirow[t]{4}{*}{4} & Jagger & -0.7 & 4.5 & 8.8 & 6.8 & 86 & 430 \\
\hline & Karl 92 & -1.5 & 5.2 & 8.2 & 7 & 79 & 440 \\
\hline & 2174 & 0.9 & 3.9 & 8.2 & 7.5 & 77 & 480 \\
\hline & 2137 & -1 & 4.1 & 8.4 & 7.9 & 83 & 500 \\
\hline
\end{tabular}

metrics used to test model performance were the RMSE and simple modeling bias (modeling heading dates minus observed heading dates) for APSIM, SIMPLACE, and MS.

\section{Results}

Calibration results of the three phenological models against observed heading dates at four sites (Fig. 1a) were analyzed for seven cultivars of winter wheat across Kansas (Fig. 4). The APSIM resulted in the largest RMSE compared to the observed heading dates for all zones (Fig. 4). Both the regular and the modified SIMPLACE models were relatively better than the APSIM at predicting heading date. However, both models had relatively poor performance ( 20 days of RMSE on average) in either semiarid crop zone 1 or moist subhumid crop zone 4 than the performance in crop zones 2 and $3(\sim 12$ days of RMSE on average). When introducing nonlinear temperature response functions (Fig. 3) and the sowing date shift factor in the MS, the MS provided a better estimate for RMSE of less than 5 days for all cultivars at any of the crop zones (Fig. 4). The MS calibrations performed the best in crop zone 2 with less than 2 days RMSE for all cultivars. There was greater variability across the crop zones than between the cultivars across Kansas (Fig. 4). Note that both APSIM and SIMPLACE models seriously underestimated the preheading development rate in 2007, a late sowing date year due to climate conditions (Figs. 4a-e). The specific MS model parameters are shown in Table 2 including nonconstant base temperatures, which suggested that on average, $\mathrm{PVT}_{t}$ and $V_{\text {sat }}$ in crop zone 2 were largest $\left(480^{\circ} \mathrm{C}\right.$ days and 85 days) when compared to the other crop zones.

Across the eight validation sites (Fig. 1b), heading dates were underestimated in APSIM but overestimated in SIMPLACE especially for Jagger, Karl 92, 2137, and 2174 (Fig. 5). The MS performed significantly better for these cultivars, which were close to the one-to-one line (Fig. 5). For all four crop zones, semiarid zone 1 had the smallest RMSE under a cold and dry climate condition (Lin et al. 2017), while zone 4 had the largest RMSE under a warm and moist subhumid climate for both APSIM and SIMPLACE (Figs. 1b and 5). In other words, when climatic conditions resulted in later heading dates, the APSIM and SIMPLACE models performed better. However, the modified model performed consistently better for all crop zones at all eight validation sites than either APSIM or SIMPLACE (Figs. $1 \mathrm{~b}$ and 5). The three models showed a better agreement for cultivar 2174 at each zone between observed heading dates and simulated heading dates (Fig. 5f).

Figure 6 provides a graphical summary of how closely the modeled heading dates agreed with the observed heading dates. The SIMPLACE model was better able to estimate heading dates of winter wheat and had on average a RMSE that was 3 days better than the APSIM model. The SIMPLACE model showed a RMSE of 9 days on average for all cultivars across four crop zones, with a range from 5 to 17 days. Both RMSE and bias increased from crop zone 1 to zone 4 (Fig. 6) in APSIM and SIMPLACE. However, the MS performed consistently and was especially accurate in warm and humid zones 3 and 4; the bias and RMSE improved as 


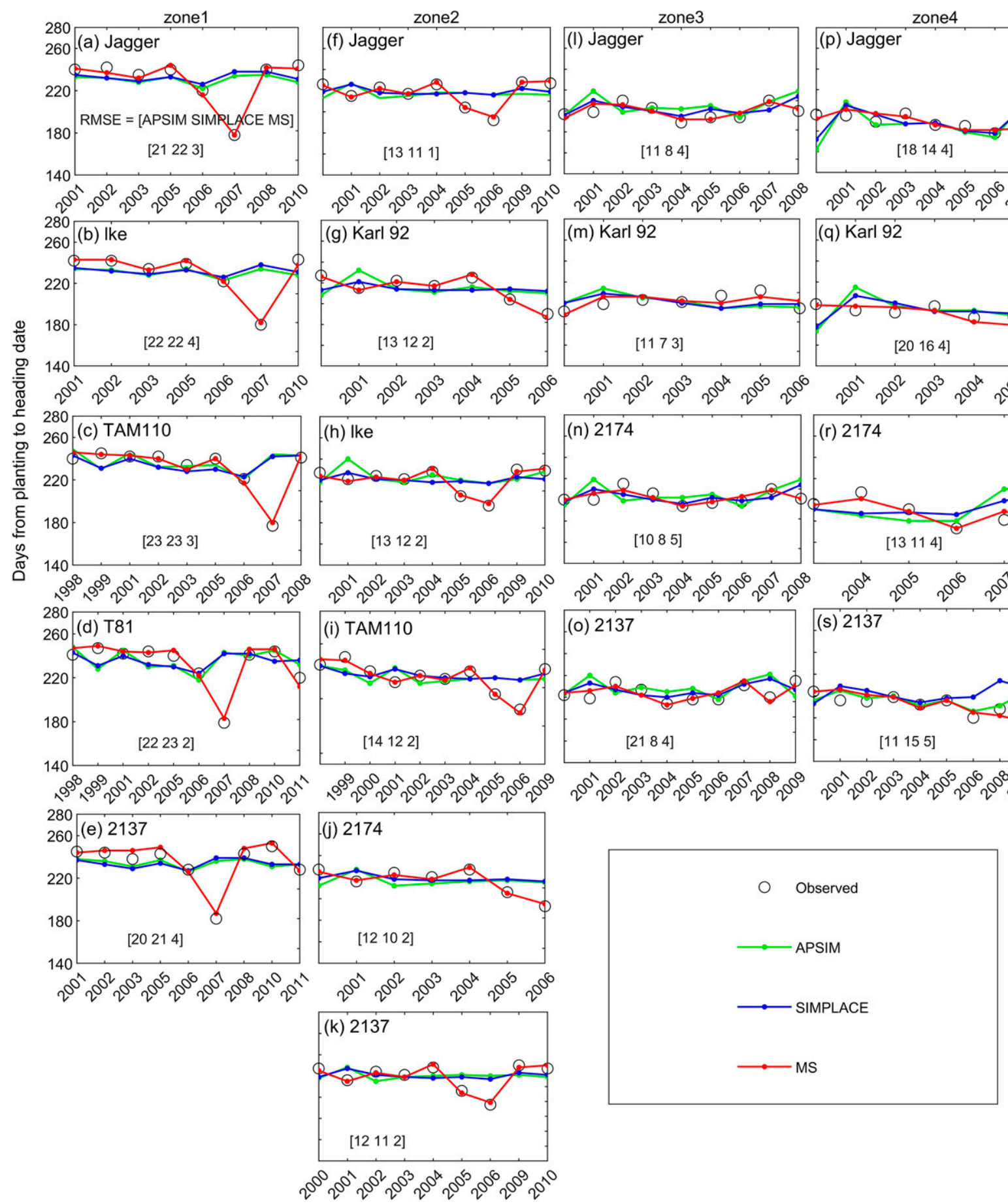

FIG. 4. Calibrated heading date time series by APSIM (green), SIMPLACE (blue), and MS models (red) and observed heading dates (black circles) for seven cultivars across the four crop zones in Kansas. The RMSE values for the three models are included in brackets.

well. Both the APSIM and SIMPLACE models result in the RMSE over 20 days on average in crop zone 4; conversely, the MS model could provide estimates with a RMSE of 4 days for all cultivars at each of the crop zones (Fig. 6). In this case, the accuracy was significantly improved by 13 days in crop zone 4 when compared to the original APSIM and SIMPLACE models.

To evaluate the impacts of shifts in sowing date on the heading date estimate in three phenological models, a correlation between sowing dates and modeling biases was shown in Fig. 7. 


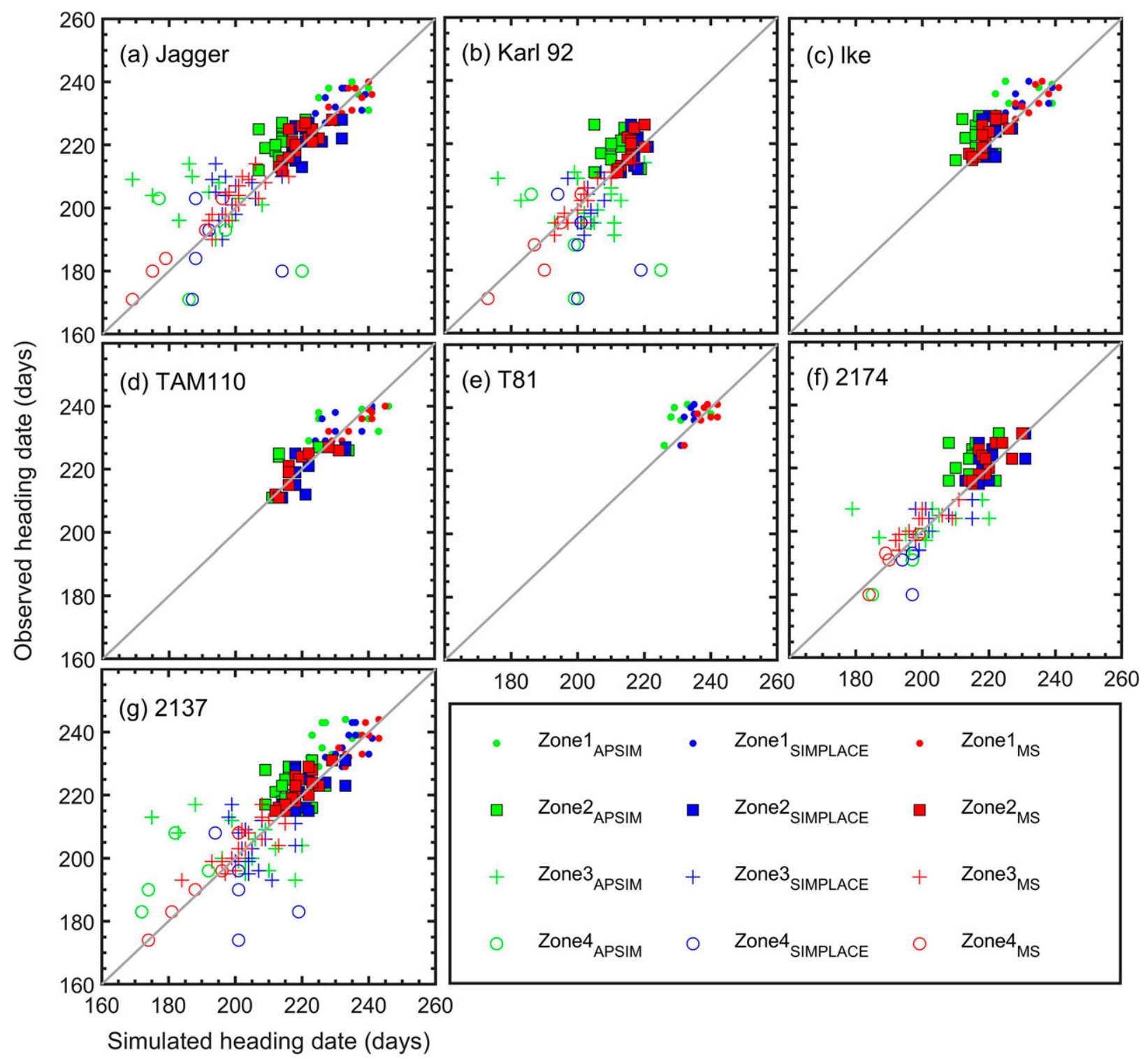

FIG. 5. Simulated heading dates against observed heading dates in APSIM (green), SIMPLACE (blue), and MS (red) models for the seven winter wheat cultivars at eight validation sites across four crop zones in Kansas (zone 1: solid dot; zone 2: square; zone 3: plus sign; zone 4: circle). Cultivars and available datasets are as described in Fig. 1. Not all cultivars were available at all locations. One-to-one line is solid line through each graph.

It was clear that both APSIM and SIMPLACE models had larger biases of predicting heading date when winter wheat's sowing dates were later or delayed especially for cultivars Jagger, Karl 92, and 2137 (Fig. 7). Although there was a slight increase in bias when sowing dates were delayed for the cultivar Karl 92 by the MS model, the overall improvement from removing the sowing date dependency in the MS model was significant (Fig. 7).

\section{Discussions}

The results in this study illustrated that the MS model improved the accuracy of estimating heading dates for all cultivars in winter wheat across Kansas, with an overall decrease of $66 \%$ and $55 \%$ in RMSE with respect to the APSIM and SIMPLACE models (Fig. 6). The performance of the MS model was in good agreement with previous studies in winter wheat for different cultivars at fixed experiment sites. For example, Streck et al. (2003) documented a RMSE of 5-6 days on average for heading date estimates in two winter wheat cultivars grown in Lincoln, Nebraska, based on their model that was the original module of phenological modeling used in the APSIM model. Although the modeling performance was similar to that observed in previous studies (Streck et al. 2003), our model was validated in a range of weather 
(a) zone 1

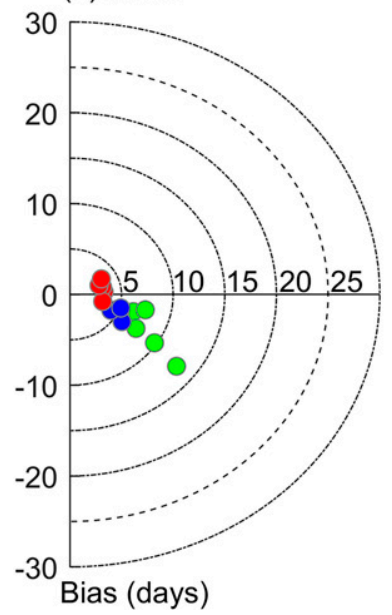

(b) zone2

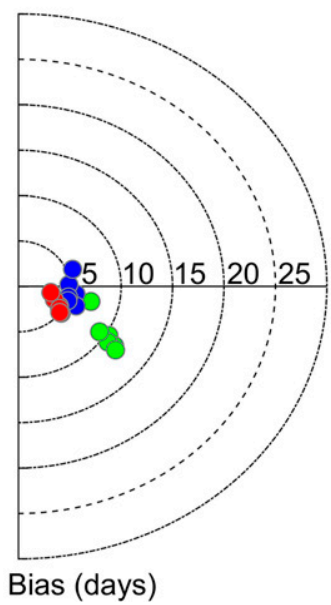

(c) zone3

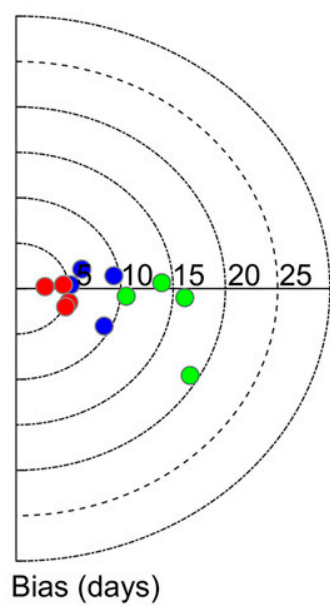

(d) zone4

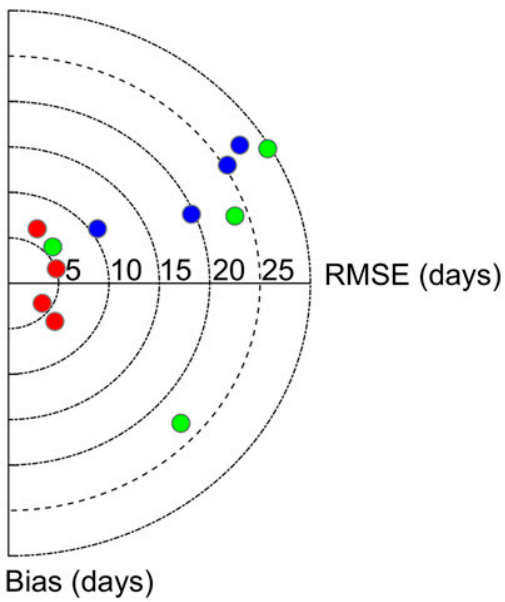

FIG. 6. Performance of APSIM (green), SIMPLACE (blue), and MS (red) models on the estimates of heading dates for seven winter wheat cultivars across four crop zones in Kansas. The $x$ axis defines the RMSE (days) and $y$ axis refers to bias between observed vs predicted heading date (days).

conditions from a cool semiarid region in northwest Kansas to the moist subhumid region in southeast Kansas as compared to a single location in the previous study. Lollato et al. (2017) documented a RMSE of $\sim 7$ days for winter wheat in the states of Kansas, Oklahoma, Colorado, and Texas, and Kawakita et al. (2020) showed a RMSE of 2-7 days on average for three wheat cultivars grown at four sites in Japan. The improved accuracy for predicting the heading date would be beneficial to disease forecasting in winter wheat growing season such as deoxynivalenol content (Hooker et al. 2002) and Fusarium head blight (De Wolf et al. 2003).

The MS model was based on simulation results showing SIMPLACE generally performed better than APSIM (Figs. 5 and 6) when used for all cultivars across four crop zones in Kansas. The SIMPLACE model includes both vernalization and photoperiod factors throughout the modeling process. The first modification was to substitute the linear temperature response function with the nonlinear TPCs. This made the crop phenology more realistic as the biological system response to temperatures is more sigmoid rather than a straight line (Shaykewich 1995). Such a nonlinear response was also adapted by previous studies for estimates of winter wheat phenology (Xue et al. 2004; Zhou and Wang 2018; Kawakita et al. 2020). The second modification was to integrate a temperature stress factor into the SIMPLACE model based on previous studies (Lollato et al. 2017; Hussain et al. 2018) indicating temperature stress negatively impacted phenological periods by changing the development rate in winter wheat. Similarly, the value of integrating a crop stress factor (e.g., crop water stress and nutrition managements) into the crop phenology model would be useful. Soil temperature might be a more direct and useful variable than air temperature in wheat phenology, especially during the early growing season (Onwuka and Mang 2018) because it directly impacts wheat development and growth, and the availability of nutrients (Lindstrom et al. 1976). However, reliable soil moisture and fertilization data are limited during growing seasons (Peng et al. 2018). The location- and cultivar-specific calibration for the basal temperature was introduced as the third modification and was supported by previous studies recommending the use of different base temperatures for different cultivars and different growing stages (Slafer and Rawson 1995; Salazar-Gutierrez et al. 2013). One explanation suggested that the cultivar- and location-dependent basal temperature helped cultivars adapt to the environmental conditions where they grew (Slafer and Savin 1991). The last modification integrated into the SIMPLACE model was the addition of sowing dates, based on a strong correlation between observed historical sowing dates and observed heading dates due partially to climate change adaptation (Fig. 2). Recent studies indicated that delayed sowing dates increased the uncertainty of modeling heading dates as changing sowing dates altered the thermal time from one phenological stage to the next (Wu et al. 2017; Hussain et al. 2018; Prajapat and Saxena 2018). In this study, the modeling performance was significantly improved if the correlations between the uncertainties of modeling the heading dates and sowing dates were examined (Fig. 7). Because this study focused on Kansas, further studies will be necessary to test the applicability of the model outside of Kansas. The model may be applicable to other areas of the U.S. winter wheat belt, but the model parameters should be further tested and identified especially when including new cultivars.

\section{Conclusions}

The primary intention of this study was to develop a simple phenology model that could be used to robustly estimate heading dates for winter wheat across Kansas. Our modified SIMPLACE (MS) model was developed by introducing TPCs curves, temperature stress factors, and sowing date shift to the 

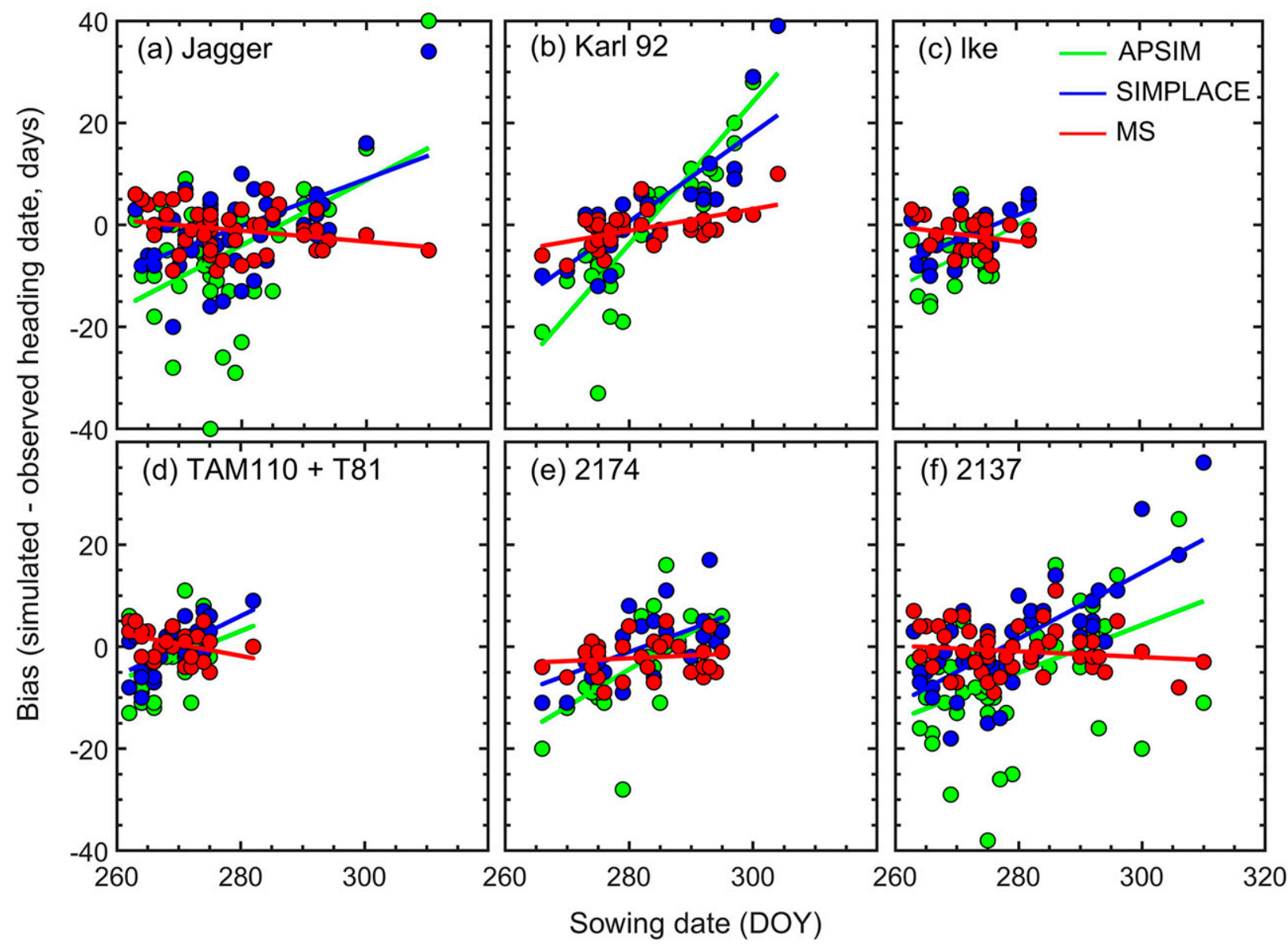

FIG. 7. Sowing date impacts on modeled heading date in APSIM (green), SIMPLACE (blue), and MS (red) for all seven cultivars at eight validation sites across four crop zones in Kansas.

original SIMPLACE model. These simple modifications improved the estimates of winter wheat heading dates. The MS model outperformed both the original APSIM and SIMPLACE models by an RMSE of 5 to 8 days on average, especially for eastern Kansas areas, where the occurrence of crop disease is relatively frequent. While only data from Kansas were used, they cover diverse climates and various winter wheat varieties commonly planted in the U.S. Great Plains. The MS model, therefore, might be applicable for hard red wheat production throughout the U.S. Great Plains region. This improvement could be instrumental for local farmers to make more timely fungicide applications to control Fusarium head blight, preserve wheat yield, and increase economic returns.

Acknowledgments. This research was supported in part by the USDA National Institute of Food and Agriculture, Hatch project 1018005, with partial funding from the Kansas Crop Improvement Association. This manuscript's Contribution Number is 20-291-J from the Kansas Agricultural Experiment Station. We thank Dallas Staley for her outstanding contribution in editing and finalizing the paper. Her work continues to be at the highest professional level. Authors have no conflict of interest to declare.

\section{REFERENCES}

Ahmed, M., M. N. Akram, M. Asim, M. Aslam, F. Hassan, S. Higgins, C. O. Stöckle, and G. Hoogenboom, 2016: Calibration and validation of APSIM-Wheat and CERES-Wheat for spring wheat under rainfed conditions: Models evaluation and application. Comput. Electron. Agric., 123, 384-401, https://doi.org/10.1016/j.compag.2016.03.015.

Bernhardt, J. R., J. M. Sunday, P. L. Thompson, and M. I. O'Connor, 2018: Nonlinear averaging of thermal experience predicts population growth rates in a thermally variable environment. Proc. Biol. Sci., 285, 20181076, https://doi.org/10. 1098/rspb.2018.1076.

Bogard, M., C. Ravel, E. Paux, J. Bordes, F. Balfourier, S. C. Chapman, J. Le Gouis, and V. Allard, 2014: Predictions of heading date in bread wheat (Triticum aestivum L.) using QTL-based parameters of an ecophysiological model. J. Exp. Bot., 65, 5849-5865, https://doi.org/10.1093/jxb/eru328.

Cane, K., and Coauthors, 2013: Ppd-B1 and Ppd-D1 and their effects in southern Australian wheat. Crop Pasture Sci., 64, 100-114, https://doi.org/10.1071/CP13086.

Chakraborty, S., and A. C. Newton, 2011: Climate change, plant diseases and food security: An overview. Plant Pathol., 60, 2-14, https://doi.org/10.1111/j.1365-3059.2010.02411.x. 
Chauhan, Y. S., M. Ryan, S. Chandra, and V. O. Sadras, 2019: Accounting for soil moisture improves prediction of flowering time in chickpea and wheat. Sci. Rep., 9, 7510, https://doi.org/ 10.1038/s41598-019-43848-6.

Chenu, K., R. Deihimfard, and S. C. Chapman, 2013: Large-scale characterization of drought pattern: A continent-wide modelling approach applied to the Australian wheatbelt-spatial and temporal trends. New Phytol., 198, 801-820, https://doi. org/10.1111/nph.12192.

Cossani, C. M., and V. O. Sadras, 2021: Nitrogen and water supply modulate the effect of elevated temperature on wheat yield. Eur. J. Agron., 124, 126227, https://doi.org/10.1016/j.eja. 2020.126227.

Cowger, C., and A. L. Sutton, 2005: The southeastern U.S. Fusarium head blight epidemic of 2003. Plant Health Prog., 6, 4, https://doi.org/10.1094/PHP-2005-1026-01-RS

Deutsch, C. A., J. J. Tewksbury, R. B. Huey, K. S. Sheldon, C. K. Ghalambor, D. C. Haak, and P. R. Martin, 2008: Impacts of climate warming on terrestrial ectotherms across latitude. Proc. Natl. Acad. Sci. USA, 105, 6668-6672, https://doi.org/10. 1073/pnas.0709472105.

De Wolf, E., L. Madden, and P. Lipps, 2003: Risk assessment models for wheat Fusarium head blight epidemics based on within-season weather data. Phytopathology, 93, 428-435, https://doi.org/10.1094/PHYTO.2003.93.4.428.

French, R., J. Schultz, and C. Rudd, 1979: Effect of time of sowing on wheat phenology in South Australia. Aust. J. Exp. Agric., 19, 89-96, https://doi.org/10.1071/EA9790089.

He, L., S. Asseng, G. Zhao, D. Wu, X. Yang, W. Zhuang, N. Jin, and Q. Yuag, 2015: Impacts of recent climate warming, cultivar changes, and crop management on winter wheat phenology across the Loess Plateau of China. Agric. For. Meteor., 200, 135-143, https://doi.org/10.1016/j.agrformet.2014.09.011.

Hooker, D., A. Schaafsma, and L. Tamburic-Ilincic, 2002: Using weather variables pre-and post-heading to predict deoxynivalenol content in winter wheat. Plant Dis., 86, 611-619, https:// doi.org/10.1094/PDIS.2002.86.6.611.

Hu, Q., A. Weiss, S. Feng, and P. S. Baenziger, 2005: Earlier winter wheat heading dates and warmer spring in the US Great Plains. Agric. For. Meteor., 135, 284-290, https://doi.org/10. 1016/j.agrformet.2006.01.001.

Hussain, J., T. Khaliq, A. Ahmad, and J. Akhtar, 2018: Performance of four crop model for simulations of wheat phenology, leaf growth, biomass and yield across planting dates. PLOS ONE, 13, e0197546, https://doi.org/10.1371/journal. pone.0197546.

Jaenisch, B. R., A. de Oliveira Silva, E. DeWolf, D. A. Ruiz-Diaz, and R. P. Lollato, 2019: Plant population and fungicide economically reduced winter wheat yield gap in Kansas. Agron. J., 111, 650-665, https://doi.org/10.2134/agronj2018.03.0223.

Jong, R. D., and K. Best, 1979: The effect of soil water potential, temperature and seeding depth on seedling emergence of wheat. Can. J. Soil Sci., 59, 259-264, https://doi.org/10.4141/ cjss 79-029.

Kawakita, S., H. Takahashi, and K. Moriya, 2020: Prediction and parameter uncertainty for winter wheat phenology models depend on model and parameterization method differences. Agric. For. Meteor., 290, 107998, https://doi.org/10.1016/j. agrformet.2020.107998.

Lin, X., J. Harrington, I. Ciampitti, P. Gowda, D. Brown, and I. Kisekka, 2017: Kansas trends and changes in temperature, precipitation, drought, and frost-free days from the 1890 s to
2015. J. Contemp. Water Res. Educ., 162, 18-30, https://doi. org/10.1111/j.1936-704X.2017.03257.x.

Lindstrom, M., R. Papendick, and F. Koehler, 1976: A model to predict winter wheat emergence as affected by soil temperature, water potential, and depth of planting. Agron. J., 68, 137141, https://doi.org/10.2134/agronj1976.00021962006800010038x.

Liu, Y., Q. Chen, Q. Ge, J. Dai, Y. Qin, L. Dai, X. Zou, and J. Chen, 2018: Modelling the impacts of climate change and crop management on phenological trends of spring and winter wheat in China. Agric. For. Meteor., 248, 518-526, https:// doi.org/10.1016/j.agrformet.2017.09.008.

Lollato, R. P., J. T. Edwards, and T. E. Ochsner, 2017: Meteorological limits to winter wheat productivity in the U.S. southern Great Plains. Field Crops Res., 203, 212-226, https://doi. org/10.1016/j.fcr.2016.12.014.

_ G. P. Bavia, V. Perin, M. Knapp, E. A. Santos, A. Patrignani, and E. D. DeWolf, 2020: Climate-risk assessment for winter wheat using long-term weather data. Agron. J., 112, 2132-2151, https://doi.org/10.1002/agj2.20168.

Maeoka, R. E., V. O. Sadras, I. A. Ciampitti, D. R. Diaz, A. K. Fritz, and R. P. Lollato, 2020: Changes in the phenotype of winter wheat varieties released between 1920 and 2016 in response to in-furrow fertilizer: Biomass allocation, yield, and grain protein concentration. Front. Plant Sci., 10, 1786, https://doi.org/10.3389/fpls.2019.01786.

McMaster, G., W. Wilhelm, and J. Morgan, 1992: Simulating winter wheat shoot apex phenology. J. Agric. Sci., 119, 1-12, https://doi.org/10.1017/S0021859600071483.

McMullen, M., G. Bergstrom, E. De Wolf, R. Dill-Macky, D. Hershman, G. Shaner, and D. Van Sanford, 2012: A unified effort to fight an enemy of wheat and barley: Fusarium head blight. Plant Dis., 96, 1712-1728, https://doi.org/10.1094/PDIS03-12-0291-FE.

Menne, M. J., C. N. Williams Jr., and R. S. Vose, 2009: The U.S. Historical Climatology Network monthly temperature data, version 2. Bull. Amer. Meteor. Soc., 90, 993-1008, https://doi. org/10.1175/2008BAMS2613.1.

Munaro, L., and Coauthors, 2020: Exploring long-term variety performance trials to improve environment-specific genotype $\times$ management recommendations: A case-study for winter wheat. Field Crops Res., 255, 107848, https://doi.org/10.1016/j. fcr.2020.107848.

Nouri, M., M. Homaee, M. Bannayan, and G. Hoogenboom, 2017: Towards shifting planting date as an adaptation practice for rainfed wheat response to climate change. Agric. Water Manage., 186, 108-119, https://doi.org/10.1016/j.agwat. 2017.03.004.

Onwuka, B., and B. Mang, 2018: Effects of soil temperature on some soil properties and plant growth. Adv. Plants Agric. Res., 8, 34-37, https://doi.org/10.15406/apar.2018.08.00288.

Paul, N. K., and D. K. Sarker, 2000: Accumulated heat units and phenology relationships in wheat as influenced by sowing dates. Bangladesh J. Bot., 29, 49-54.

Peng, B., K. Guan, M. Chen, D. M. Lawrence, Y. Pokhrel, A. Suyker, T. Arkebauer, and Y. Luc, 2018: Improving maize growth processes in the community land model: Implementation and evaluation. Agric. For. Meteor., 250-251, 64-89, https://doi.org/10.1016/j.agrformet.2017. 11.012.

Prajapat, A. L., and R. Saxena, 2018: Thermal requirements of wheat (Triticum aestivum L.) cultivars under different growing environments. Int. J. Chem. Stud., 6, 17-22. 
Prank, M., S. C. Kenaley, G. C. Bergstrom, M. Acevedo, and N. M. Mahowald, 2019: Climate change impacts the spread potential of wheat stem rust, a significant crop disease. Environ. Res. Lett., 14, 124053, https://doi.org/10.1088/1748-9326/ ab57de.

Rezaei, E. E., S. Siebert, H. Hüging, and F. Ewert, 2018: Climate change effect on wheat phenology depends on cultivar change. Sci. Rep., 8, 4891, https://doi.org/10.1038/s41598-01823101-2.

Ritchie, J., and D. Nesmith, 1991: Temperature and crop development. Modeling Plant and Soil Systems, Agron. Monogr., Vol. 31, Wiley, 5-29, https://doi.org/10.2134/agronmonogr31.c2.

Sacks, W. J., D. Deryng, J. A. Foley, and N. Ramankutty, 2010: Crop planting dates: An analysis of global patterns. Global Ecol. Biogeogr., 19, 607-620, https://doi.org/10.1111/j.14668238.2010.00551.x.

Salazar-Gutierrez, M., J. Johnson, B. Chaves-Cordoba, and G. Hoogenboom, 2013: Relationship of base temperature to development of winter wheat. Int. J. Plant Prod., 7, 741-762.

Sassenrath, G. F., J. Farney, and R. Lollato, 2019: Impact of fungicide and insecticide use on wheat production in a highrainfall environment. Crop Forage Turfgrass Manage., 5, 190008, https://doi.org/10.2134/cftm2019.01.0008.

Shah, D., J. Molineros, P. Paul, K. Willyerd, L. Madden, and E. D. De Wolf, 2013: Predicting Fusarium head blight epidemics with weather-driven pre- and post-anthesis logistic regression models. Phytopathology, 103, 906-919, https://doi. org/10.1094/PHYTO-11-12-0304-R.

Shaykewich, C., 1995: An appraisal of cereal crop phenology modelling. Can. J. Plant Sci., 75, 329-341, https://doi.org/10. 4141/cjps95-057.

Shroyer, J., and Coauthors, 1996: Kansas crop planting guide. Kansas State University Agricultural Experiment Station and Cooperative Extension Service L-818, 8 pp., https:// bookstore.ksre.ksu.edu/pubs/1818.pdf.

Slafer, G., and R. Savin, 1991: Developmental base temperature in different phenological phases of wheat (Triticum aestivum). J. Exp. Bot., 42, 1077-1082, https://doi.org/10.1093/jxb/ 42.8.1077.

— with genotype and stage of development in wheat. Plant Cell Environ., 18, 671-679, https://doi.org/10.1111/j.1365-3040.1995. tb00568.x.

Staggenborg, S., D. Whitney, D. Fjell, and J. Shroyer, 2003: Seeding and nitrogen rates required to optimize winter wheat yields following grain sorghum and soybean. Agron. J., 95, 253-259, https://doi.org/10.2134/agronj2003.2530.

Streck, N. A., A. Weiss, Q. Xue, and P. S. Baenziger, 2003: Improving predictions of developmental stages in winter wheat: A modified Wang and Engel model. Agric. For. Meteor., 115, 139-150, https://doi.org/10.1016/S0168-1923(02)00228-9.

Thiry, D., R. G. Sears, J. P. Shroyer, and G. M. Paulsen, 2002: Planting date effects on tiller development and productivity of wheat. Kansas State University Agricultural Experiment Station and Cooperative Extension Service, 4 pp., https:// www.ksre.k-state.edu/historicpublications/pubs/SRL133.pdf.

Tollenaar, M., J. Fridgen, P. Tyagi, P. W. Stackhouse Jr., and S. Kumudini, 2017: The contribution of solar brightening to the US maize yield trend. Nat. Climate Change, 7, 275-278, https://doi.org/10.1038/nclimate3234.

Vasseur, D. A., and Coauthors, 2014: Increased temperature variation poses a greater risk to species than climate warming. Proc. Biol. Sci., 281, 20132612, https://doi.org/10.1098/rspb. 2013.2612.

Vrugt, J. A., C. J. Ter Braak, M. P. Clark, J. M. Hyman, and B. A. Robinson, 2008: Treatment of input uncertainty in hydrologic modeling: Doing hydrology backward with Markov chain Monte Carlo simulation. Water Resour. Res., 44, 44, https://doi.org/10.1029/2007WR006720.

Wallach, D., and Coauthors, 2021: Multi-model evaluation of phenology prediction for wheat in Australia. Agric. For. Meteor., 298-299, 108289, https://doi.org/10.1016/j.agrformet. 2020.108289.

Williams, J., C. Jones, J. Kiniry, and D. A. Spanel, 1989: The EPIC crop growth model. Trans. ASAE, 32, 497-511, https:// doi.org/10.13031/2013.31032.

Wu, L., L. Feng, Y. Zhang, J. Gao, and J. Wang, 2017: Comparison of five wheat models simulating phenology under different sowing dates and varieties. Agron. J., 109, 1280-1293, https://doi.org/10.2134/agronj2016.10.0619.

Xue, Q., A. Weiss, and P. S. Baenziger, 2004: Predicting phenological development in winter wheat. Climate Res., 25, 243 252, https://doi.org/10.3354/cr025243.

Yajam, S., and H. Madani, 2013: Delay sowing date and its effect on Iranian winter wheat cultivars yield and yield components. Ann. Biol. Res., 4, 270-275.

Zambreski, Z. T., 2020: Advancing climate resilient agriculture in the US Great Plains: Modeling climate dynamics and impacts on crop production. Ph.D. dissertation, Kansas State University, 207 pp.

Zheng, B., K. Chenu, A. Doherty, and S. Chapman, 2015: The APSIM-wheat module (7.5 R3008). Agricultural Production Systems Simulator Initiative, $44 \mathrm{pp}$.

Zhou, G., and Q. Wang, 2018: A new nonlinear method for calculating growing degree days. Sci. Rep., 8, 10149, https://doi.org/ 10.1038/s41598-018-28392-z. 